\title{
Notes on the Checkered Keelback, Xenochrophis piscator (Schneider 1799), in Gujarat, India
}

\author{
Dikansh S. Parmar
}

Department of Biosciences, Veer Narmad South Gujarat University, Surat, Gujarat India (ophiophagus_hannah10@yahoo.com)

Photographs by the author except where noted.

$\mathrm{T}$ 'he Checkered Keelback (Xenochrophis piscator, Fig. 1) is a common, medium-sized, keel-scaled, non-venomous, oviparous natricid with a wide distribution throughout much of southern Asia. Its range includes most of India (Fig. 2) but excludes the Andaman and Nicobar Islands (Whitaker and Captain 2008). In Gujarat, this species occurs from the lowlands to at least $1,000 \mathrm{~m}$ in the vicinity of a hill town like Saputara. These semi-aquatic snakes are closely associated with streams, lakes, ponds, rivers, and paddy fields, where they can be active by both day and night. Snakes of both sexes are frequent roadkills during the rainy season (Fig. 3), and many individuals are encountered on roads at night. On 28 July 2010, a 1,310-mm long individual was obtained from the Hojiwala Estate in the Surat District and taken into captivity; it had just consumed a frog and it was not moving quickly.
After a few days, it egested the bones of the frog (Fig. 4). Juveniles feed primarily on tadpoles, frogs, and aquatic insects, whereas adults feed primarily on fishes and frogs but occasionally take rodents and birds (Whitaker and Captain 2008).

Females are larger than males. Whitaker and Captain (2008) reported a maximum total length of $1,750 \mathrm{~mm}$, but Vishal Mistry (pers. comm.) informed me of a snake from Gujarat that had a total length of $1,889.8 \mathrm{~mm}$. The average length of rescued snakes is about $1 \mathrm{~m}$. Checkered Keelbacks are quite variable in color, pattern, and some aspects of morphology. In Gujarat, I have encountered snakes with dorsal ground colors ranging from pink or reddish, dull olive-green (Fig. 5), and olive brown to pale or golden yellow and even white. Very dark brown to black markings, often forming a checkerboard pattern or irregular series of spots, range from

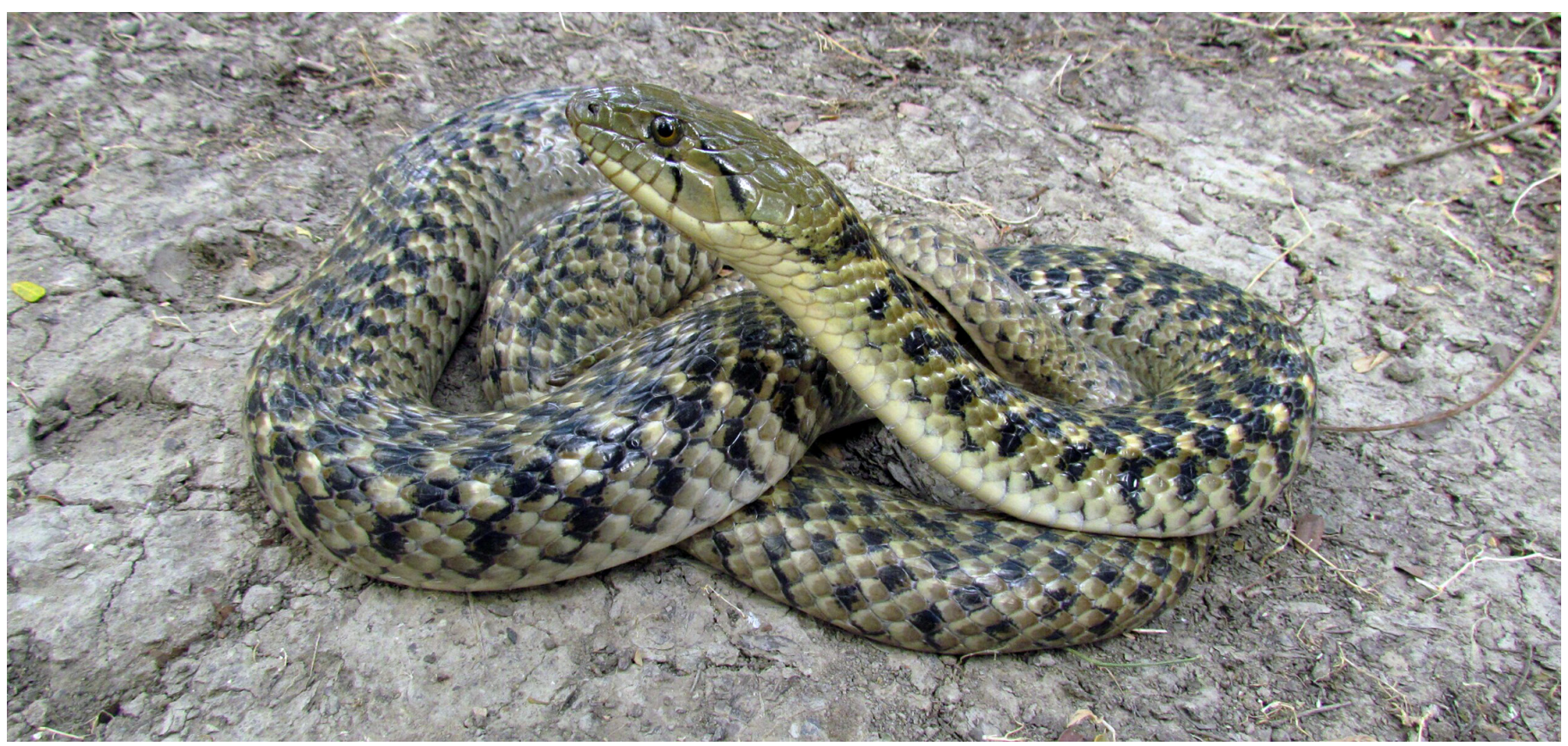

Fig. 1. A Checkered Keelback (Xenochrophis piscator), the most frequently encountered semi-aquatic snake in India. 


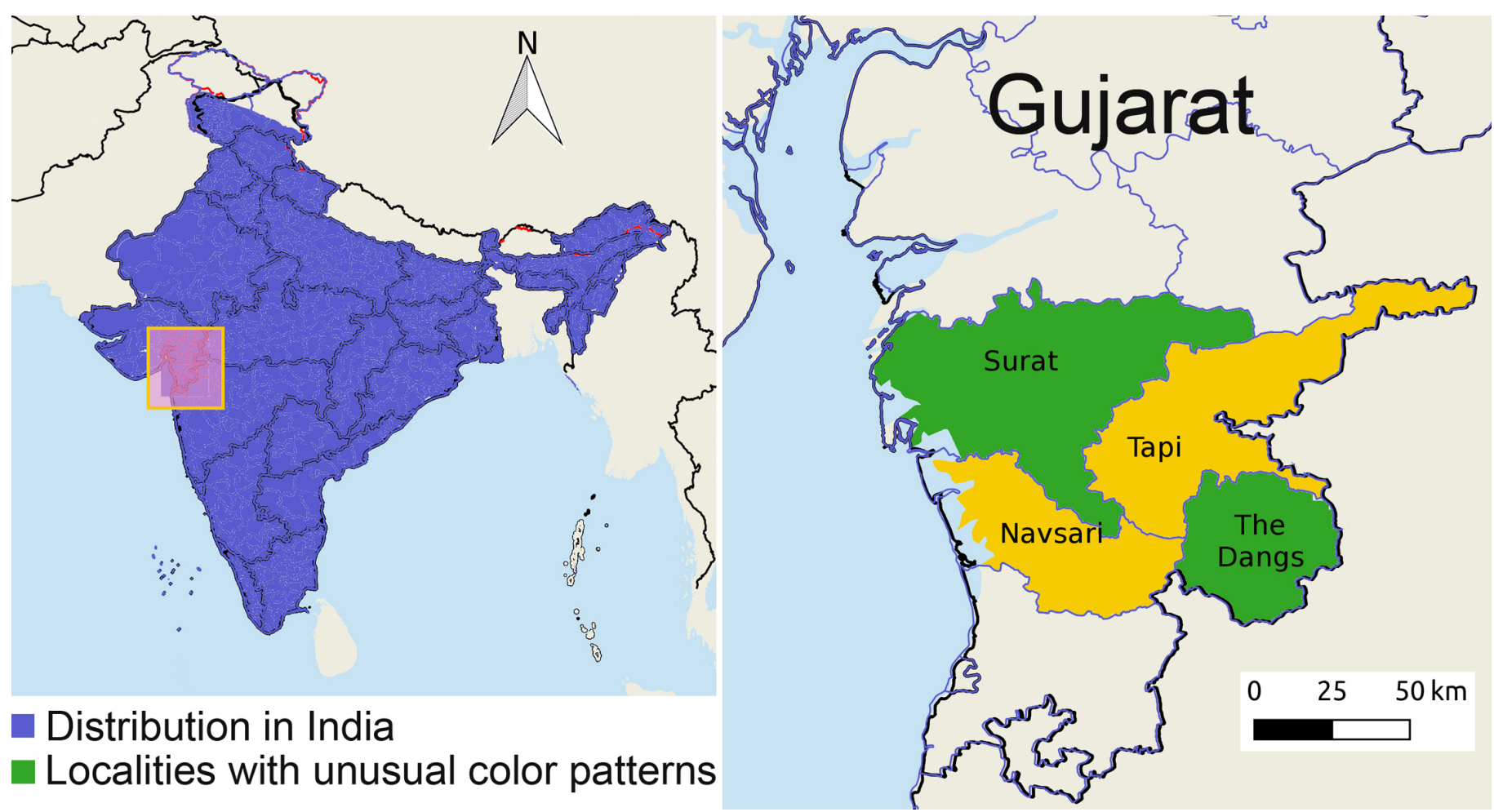

Fig. 2. Map showing the nearly nationwide distribution of Checkered Keelbacks (Xenochrophis piscator) in India. Completely black and black-and-yellow snakes are herein reported from districts colored green and might also occur in those colored yellow. Map by Jenis R. Patel.

absent or faint to extensive, with the dark color in most snakes covering $\leq 40 \%$ of the dorsum. Black-and-yellow snakes are uncommon in Gujarat, having been reported only from the Saputara Hill Station, Ahwa, and Waghai. Many of these individuals have black covering $75-80 \%$ of the dorsum (Fig. 6). Herein I also provide the first record of a snake from Gujarat (Surat District) with totally black back and sides (Fig. 7). The only other record of a black Checkered Keelback of which I am aware was from the state of Maharashtra (Mehul Thakur, pers. comm.). Regardless of dorsal color, the venter usually is uniformly white or pale yellowish cream. Dorsal scale rows number 19:19:17. The tail comprises one fourth to one third of the total length. Snakes from The Dangs gener-

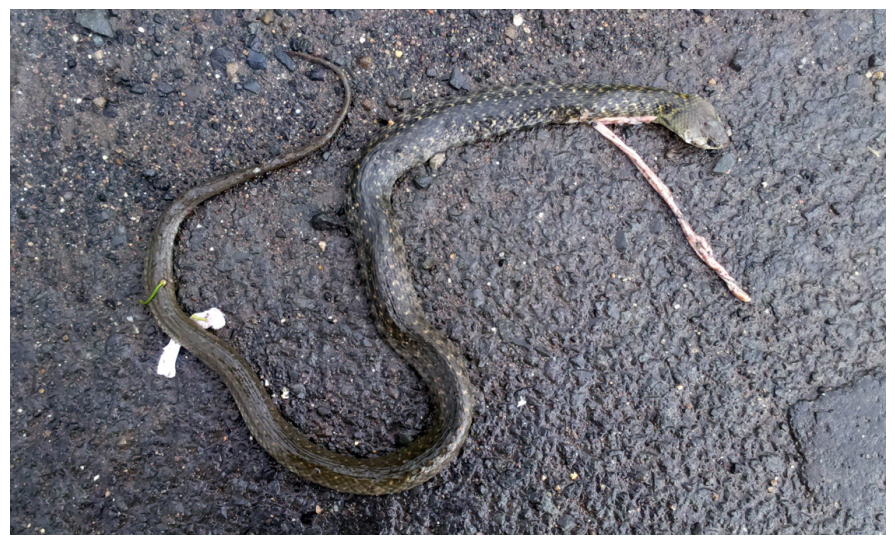

Fig. 3. Checkered Keelbacks (Xenochrophis piscator), such as this male, are frequent roadkills during the rainy season. ally have the same scalation as those found in other regions, differing only in having 8-9 (as opposed to 10-11) infralabials. The heads of snakes in that area also differ slightly from those found elsewhere in being more rounded and having a more slightly tapering snout.

Reproduction.-Xenochrophis piscator is known to mate in October, and females lay eggs from November to May, usually in a nest hole or in the ground near water (Daniel 1983). In my experience, eggs of this species need high levels of moisture and medium to low temperatures during incubation. Unlike most snakes, $X$. piscator demonstrates parental care, females staying with their clutches of 8-91 eggs during the incuba-

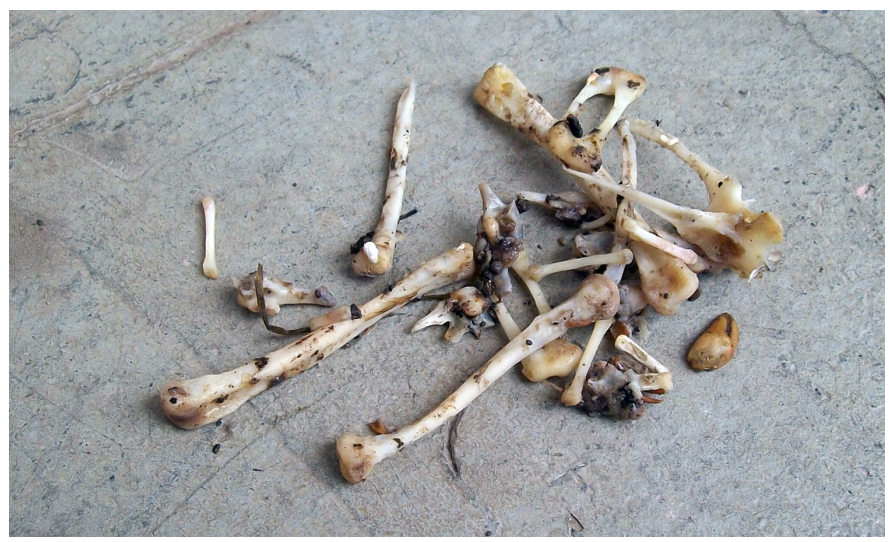

Fig. 4. Frog bones egested by a Checkered Keelback (Xenochrophis piscator) from the Hojiwala Estate in the Surat District. 


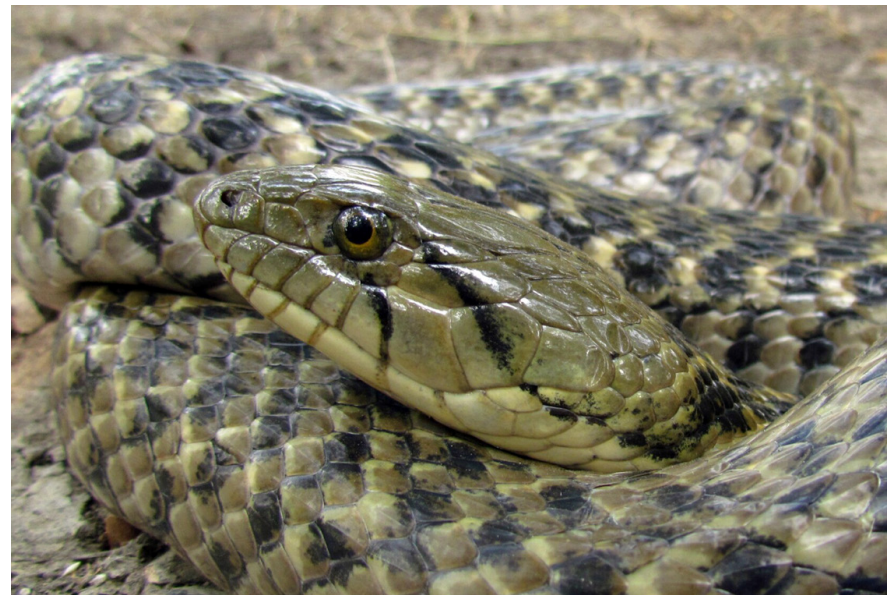

Fig. 5. A Checkered Keelback (Xenochrophis piscator) with a dull olive ground color and a moderate amount of black patterning.

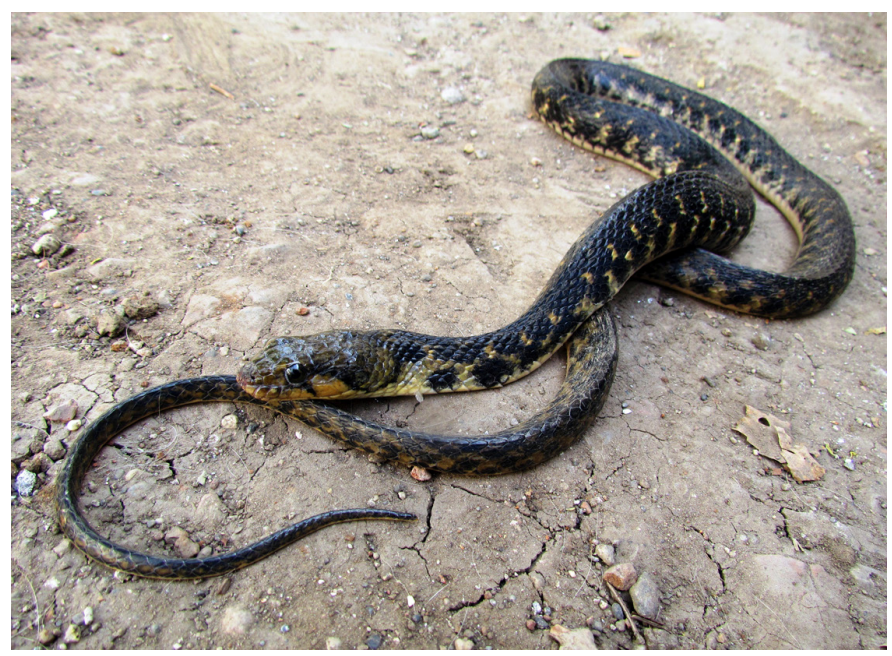

Fig. 6. A black-and-yellow Checkered Keelback (Xenochrophis piscator) with extensive black markings from the Saputara Hill Station (elev. 1,000 $\mathrm{m})$ in The Dangs District.

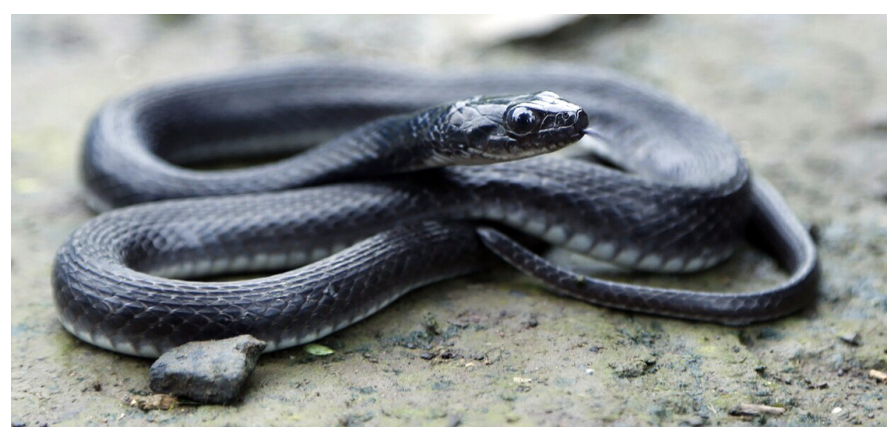

Fig. 7. First record of a Checkered Keelback (Xenochrophis piscator) with a completely black dorsum. Photograph by Mehul Thakur.

tion period of 37-60 days (Daniel 1983; pers. obs.; Fig. 8). A record number of 120 eggs was laid by a Xenochrophis piscator in the Anand District of Gujarat (D.S. Patel, pers. comm.). Eggs average $18 \times 27 \mathrm{~mm}$ (Daniel 1983), but those laid by captive snakes in my care were slightly larger $(29$ x $20 \mathrm{~mm})$.
Table 1. Data on Checkered Keelback (Xenochrophis piscator) hatchlings $(\mathrm{SVL}=$ snout-vent length; $\mathrm{TL}=$ tail length; $\mathrm{TOL}=$ total length). Midbody girth was $13 \mathrm{~mm}$ in all hatchlings. Hatchlings that survived after exposure to phenol are indicated by a checkmark $(\sqrt{ })$.

\begin{tabular}{lcc} 
Sex & SVL + TL $=$ TOL $(\mathbf{m m})$ & Survived \\
\hline $\mathrm{F}$ & $178+63=241$ & $\sqrt{ }$ \\
\hline $\mathrm{F}$ & $178+63=241$ & $\sqrt{ }$ \\
\hline $\mathrm{F}$ & $178+63=241$ & - \\
\hline $\mathrm{F}$ & $165+63=228$ & - \\
\hline $\mathrm{F}$ & $165+63=228$ & $\sqrt{ }$ \\
\hline $\mathrm{M}$ & $165+63=228$ & $\sqrt{ }$ \\
\hline $\mathrm{M}$ & $165+63=228$ & - \\
\hline $\mathrm{M}$ & $165+63=228$ & - \\
\hline $\mathrm{M}$ & $153+63=216$ & $\sqrt{ }$ \\
\hline $\mathrm{M}$ & $140+63=203$ &
\end{tabular}

At 1630 h on 17 April 2010, we rescued ten Xenochrophis piscator hatchlings ( 5 males, 5 females) from a residential area near the canal in Panas Gam, Surat District. The hatchlings were in a burrow under a tree and most were moving rapidly when first encountered. Local people, who are afraid of snakes, had used phenol (an antiseptic and disinfectant) in an attempt to kill them before we were able to intercede. We soaked all individuals in a tub filled with fresh water (Fig. 9) in an effort to minimize the effects of the phenol; however, five snakes (2 males, 3 females) died. All were measured, sexed, and photographed (Table 1). Following data collection, the surviving hatchlings were released into natural habitat.

Defensive behaviors. - Xenochrophis piscator employs a number of defensive strategies. It will flatten the head, extending the neck ribs and raising the forebody into a position in which it can be mistaken for a cobra (Whitaker and Captain 2008). If grasped, it strikes rapidly with great determination; Daniel (1983) noted that the Checkered Keelback is among the most vicious of Indian snakes. It secretes a malodorous musk (Desai 2017). It will roll its body (similar to the "death roll" of a crocodile) in an effort to escape. Also, in my experience and unlike most snakes, its tail breaks easily (often when rolling its body) and, as in many lizards that shed their tails, the stillmoving tail could distract a predator, allowing the snake time to escape. During rescues, we sometimes find snakes with partial tails. To avoid damage to a snake's tail during a rescue, we always hold Checkered Keelbacks by the body.

In addition, when attacked by predators, $X$. piscator will feign death (MacDonald 1947; Daniel 1983). However, I have experienced this behaviour only four times in 18 years of rescue work. In one instance, a juvenile rescued from a marshy location bit my hand, so I placed it in a transparent 


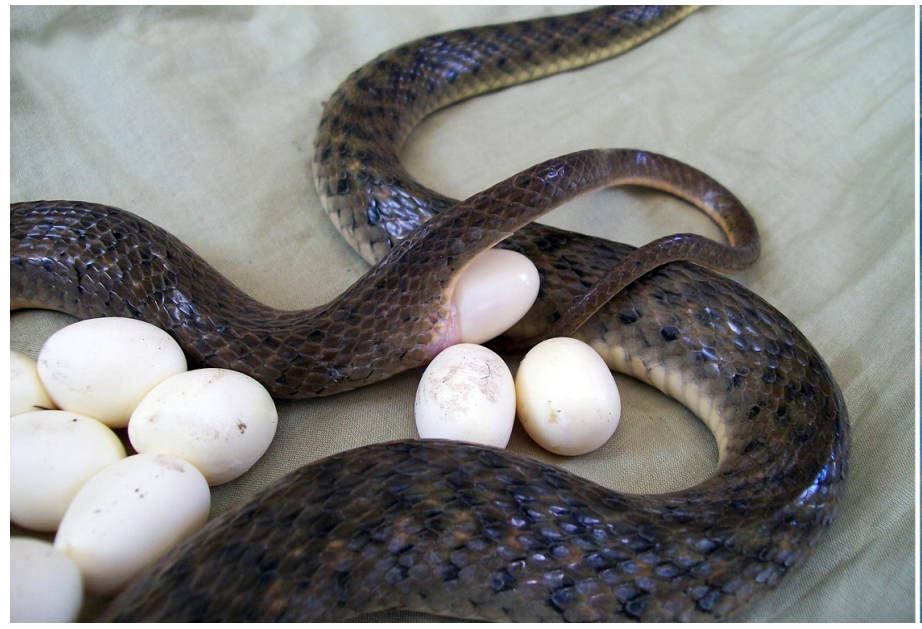

Fig. 8. Checkered Keelbacks (Xenochrophis piscator) laying eggs.

ventilated bottle where it appeared to be lifeless. When I gently shook the bottle the snake did not move, so I took it out and placed it on ground. Within a minute, it attempted to escape. I caught the snake and returned it to the bottle, where it again acted as if it was dead. I eventually released that little snake into appropriate habitat.

On another occasion, I experienced another strategy that I do not believe has been documented in snakes. I had rescued a female with eggs from under the roots of a tree when it suddenly vomited blood on my hands and the lower third of its body became completely slack, hanging motionless. My hands were covered in blood as blood continued to flow from its mouth. Locals residents assumed that I had hurt this snake that I had been handling so gently. I placed it in a snake bag, which quickly became soiled with blood. At the rescue cen-

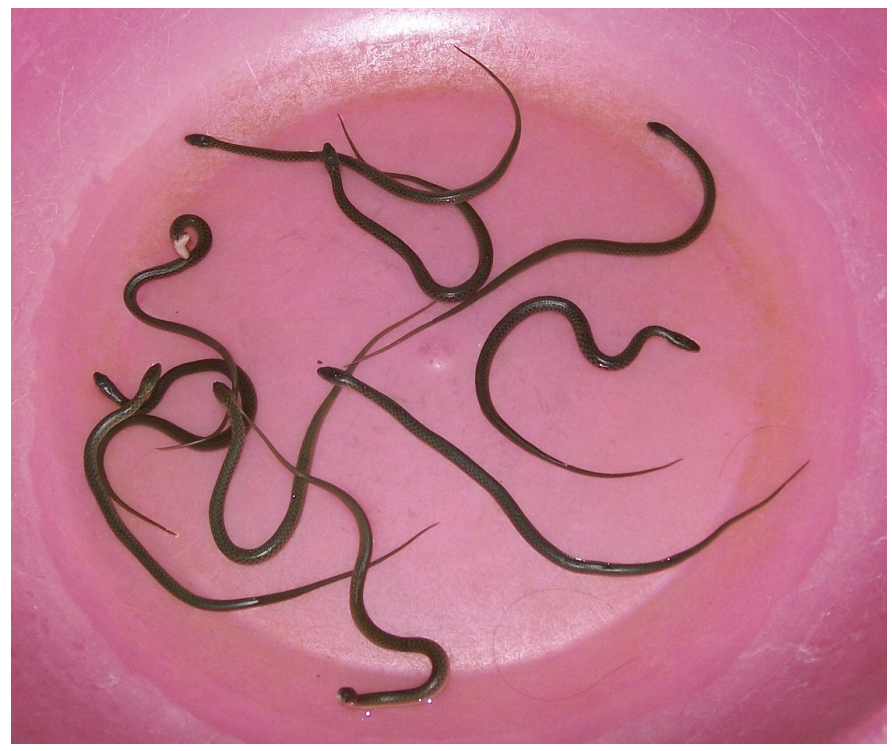

Fig. 9. Hatchling Checkered Keelbacks (Xenochrophis piscator) in a container with fresh water in an effort to minimize the effect of phenol to which they were exposed prior to their rescue.

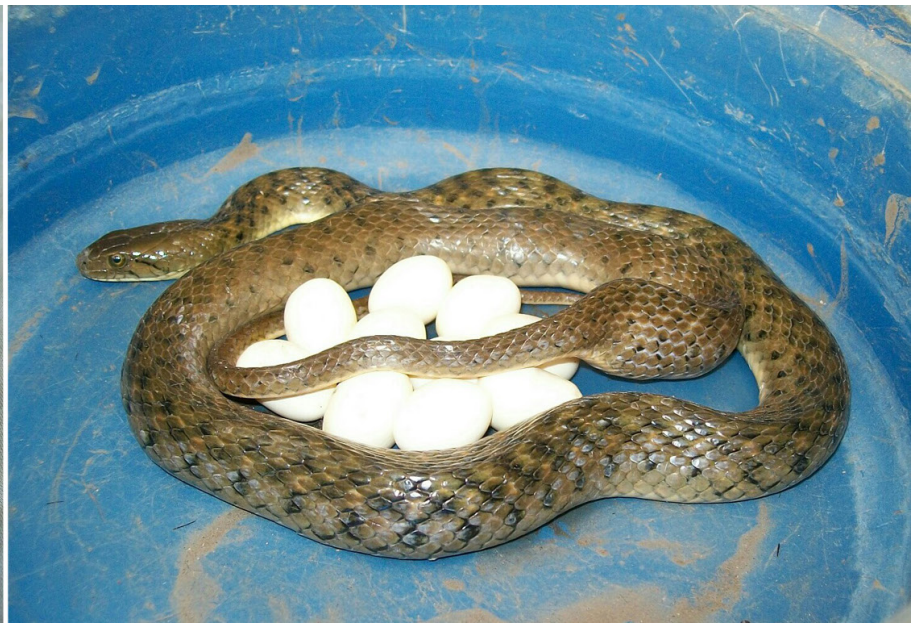

ter, I noticed that the snake was still moving in the bag, so I placed it in a vivarium for observation. It subsequently moved actively, flattening its neck and raising its forebody in response to my presence. After two days of observation and no further symptoms of any injury, I released the snake (Fig. 10).

Conservation.-Xenochrophis piscator is a commonly encountered species. Its conservation status has not been formally assessed but, according to IUCN Red List criteria (IUCN Species Survival Commission 2012), its status would be Least Concern. However, threats exist. Principal among these are loss of habitat, largely attributable to drying water bodies and development. Other threats include industrial effluents dumped into rivers, road mortality, plus fear and a lack of awareness about snakes, which are killed indiscriminately by many locals, necessitating the release of rescued snakes into increasingly imperilled habitats. Harmful chemicals and pesticides used in fields to protect crops from rats also eliminate an essential food source for snakes. These issues are not limited to Checkered Keelbacks or even snakes in general, nor are they restricted to India. Naturalists throughout the world must address these and related concerns if natural habitats and the associated wildlife are to survive.

\section{Acknowledgements}

I am thankful to Ajay Desai, author of Sarp Sandarbh Information about the Snakes of Gujarat, for his support; Dhaval S. Patel, president of Vidhyanagar Nature Club, Anand District, Gujarat, for providing information about the 120 eggs; Mehul Thakur for providing a photograph and locality information regarding the black snake mentioned in this paper; Jenis R. Patel of the Nature Conservation Foundation for creating the map; Vasudev Limbachiya for his support of snake rescues; and Vishal Mistry for providing information on the maximum length of the snake from the Anand District, Gujarat. 


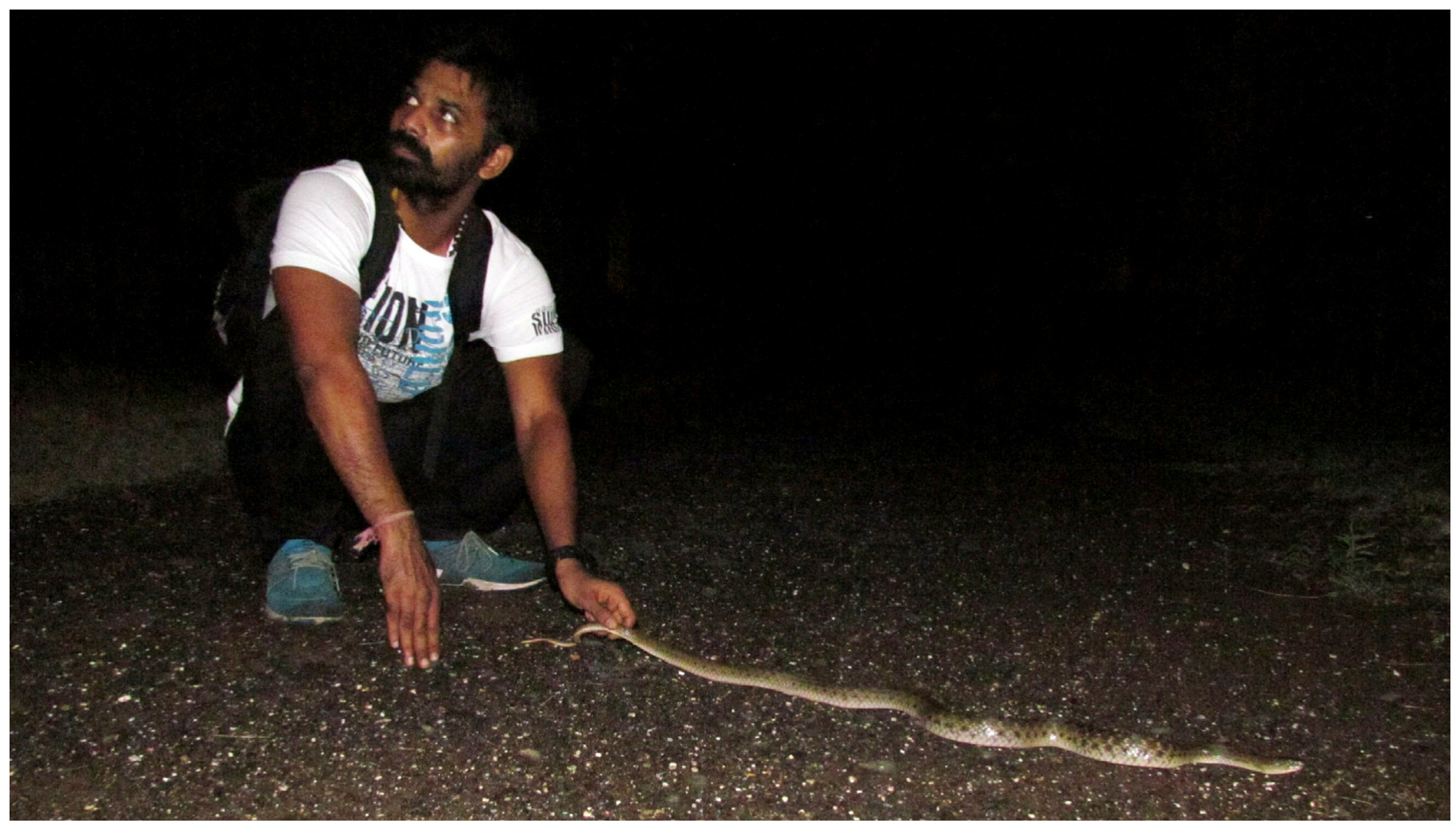

Fig. 10. A Checkered Keelback Snake (Xenochrophis piscator) that had vomited blood during its rescue being released near a lake at night after two days of observation. Photograph by Vasudev Limbachiya.

\section{Literature Cited}

Daniel, J.C. 1983. The Book of Indian Reptiles. Oxford University Press, Bombay, India. Desai, A. 2017. Sarp Sandarbh. Information about the Snakes of Gujarat. Prakruti Mitra Mandal, Dahod, Gujarat.

IUCN Species Survival Commission. 2012. IUCN Red List Categories and Criteria.
Version 3.1. Second edition. International Union for Conservation of Nature and Natural Resources, Gland, Switzerland and Cambridge, United Kingdom.

MacDonald, A.St.J. 1947. Shamming death. Journal of the Bombay Natural History Society 47: 173.

Whitaker, R. and A. Captain. 2008. Snakes of India. The Field Guide. Draco Books, Chennai. 